\title{
Optical modeling of extraoral defects
}

\author{
Bernd Reitemeier, DDS, MSD, PhD, ${ }^{a}$ Gunther Notni, DS, MSME, ${ }^{b}$ Matthias Heinze, DS, ${ }^{c}$ \\ Christine Schöne, DS, MSME, ${ }^{d}$ Annette Schmidt, DDS, MSD, ${ }^{e}$ and Dieter Fichtner, DS, MSME, \\ $\mathrm{PhD}^{\mathrm{f}}$
}

Medical Faculty, Technical University of Dresden, Dresden; Fraunhofer Institute for Applied Optics and Precision Engineering, Jena, Germany

\begin{abstract}
In order to reduce the stress caused to patients by conventional methods of modeling using computed tomography (CT) or magnetic resonance imaging (MRI), an optical modeling process has been developed for extraoral defects and body areas. The selected body part is digitized using optical 3-coordinate measuring technology, providing an extensive data record. This is adapted for further use by equalizing the point clouds to obtain a Computer Aided Design (CAD) model, which is converted to a physical model by means of a stereolithographic process. With this technology, the patient's physical and psychological stress may be reduced. This article describes a technique for optical modeling of an ocular prosthesis. (J Prosthet Dent 2004;91:80-4.)
\end{abstract}

ntil recently, conventional impression materials such as silicones or irreversible hydrocolloid and technologies (single or dual cycle processes with or without molding aids) have been used to fabricate maxillofacial prostheses, individual respiratory masks, and extraoral radiation devices. Depending on the impression material and the method of positioning the patient during the impression procedure, displacement of the soft tissues can occur. ${ }^{1}$ Various materials have been used to support the impression materials during the procedure. ${ }^{2}$ Industrially preproportioned, mechanically miscible, irreversible hydrocolloids (for example, Algicap; Ivoclar, Schaan, Fuerstentum, Liechtenstein) have been used. These materials had the advantage of preventing errors in proportioning and mixing when silicones were used; cartridge systems provided the same advantage. ${ }^{3-8}$

Newer technologies are oriented to computed tomography (CT) or magnetic resonance imaging (MRI) data, whereby the patient undergoes considerable exposure to radiation. ${ }^{9-11}$ To avoid these disadvantages, an optical modeling process for extraoral defects and body areas was developed. The development was based on experience in the collection of digitized data for toothrelated, model-dependent representations. ${ }^{12-15}$ The optical 3-dimensional (3-D) scanning unit provides a point cloud or virtual model of the face. The primary principle

aProfessor, Medical Faculty, Department of Prosthetic Dentistry, Technical University of Dresden.

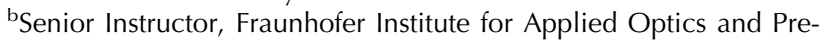
cision Engineering.

${ }^{\mathrm{C}}$ Research Assistant, Fraunhofer Institute for Applied Optics and Precision Engineering.

${ }^{\mathrm{d}}$ Senior Instructor, Institute of Production Engineering, Department of Engineering, Technical University of Dresden.

eResearch Assistant, Medical Faculty, Department of Prosthetic Dentistry, Technical University of Dresden.

fProfessor and Chairman, Institute of Production Engineering, Department of Engineering, Technical University of Dresden. used to obtain digitized data for extraoral areas is the method of structured light illumination with a digitallight projection unit. ${ }^{16,17}$ Use of 3-D scanning in medical applications has specific system requirements: the body part (for example, the face) should be viewed from different directions simultaneously; the measurements should be made within seconds; and the system should be mobile and simple to use.

Such a system was developed by the Fraunhofer Institute for Applied Optics and Precision Engineering in Jena, Germany. It is a mobile, multiview 3-D measuring system (called "kolibri-mobile") based on self-calibrating fringe projection technology, which facilitates the fully automatic recording of the body part from various directions in one measuring process. ${ }^{17}$ Thus, it is possible to view the face in one complete sweep, from ear to ear and from below the chin to the forehead. The maximum field diameter of the system (of the area that can be recorded at one time) is $650 \mathrm{~mm}$. Therefore, the complete human face can be recorded in a single operation.

The face is illuminated by 2 grating sequences (grey code combined with four, 90 -degree phase-shifted sinusoidal intensities) rotated 90 -degrees from different directions. The observing cameras capture these fringe pictures simultaneously, resulting in at least 4 phase values for each pixel of the camera. Using these phase values, the 3-D coordinates are calculated. In the measuring situation of the "kolibri-mobile" system, the object is illuminated from different directions by means of a network of fixed mirrors $\left(M_{21}, M_{22}, M_{23}, M_{24}\right.$, and $\mathrm{M}_{25}$ ) and simultaneously observed from different directions (Figs. 1 and 2). The switching of the projection direction is done by the rotating central mirror $M_{1}$. The position and number of the mirrors and cameras can be selected, thereby adapting the system for the relevant body part. Optimum measurement of an extraoral defect involves 4 cameras and 5 projection directions; where more measurements are made from below, 2 of 


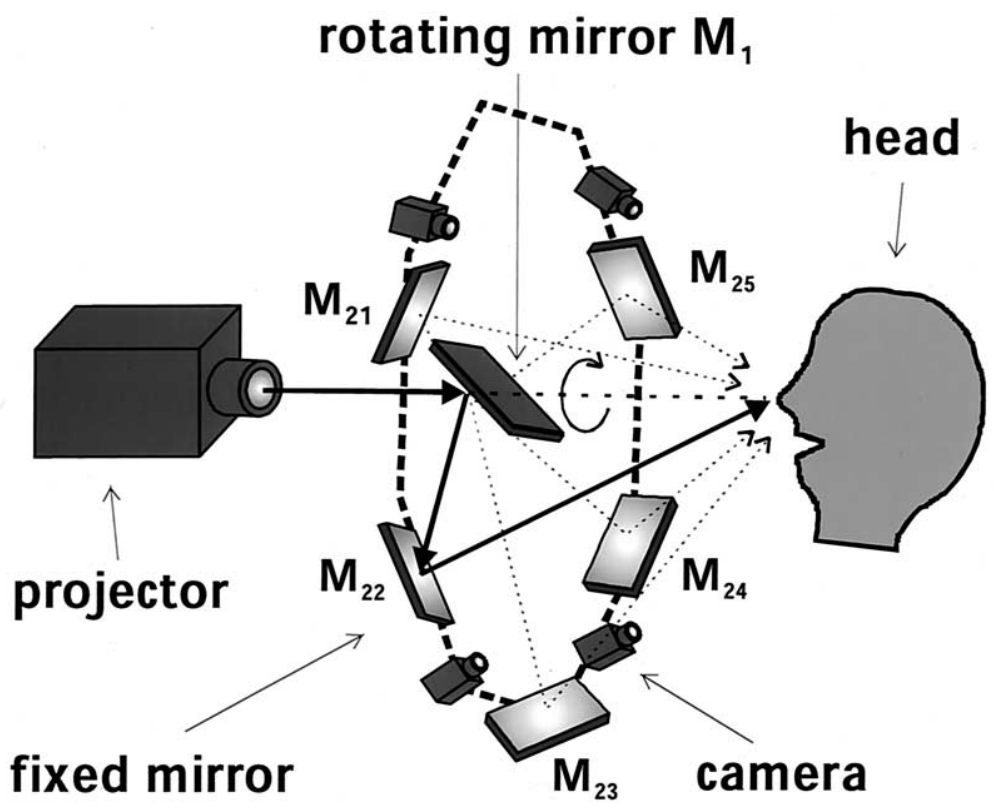

Fig. 1. Schematic of measurement instrumentation - kolibri-mobile. $\left(M_{21}, M_{22}, M_{23}, M_{24}, M_{25}\right.$, represent fixed mirrors).

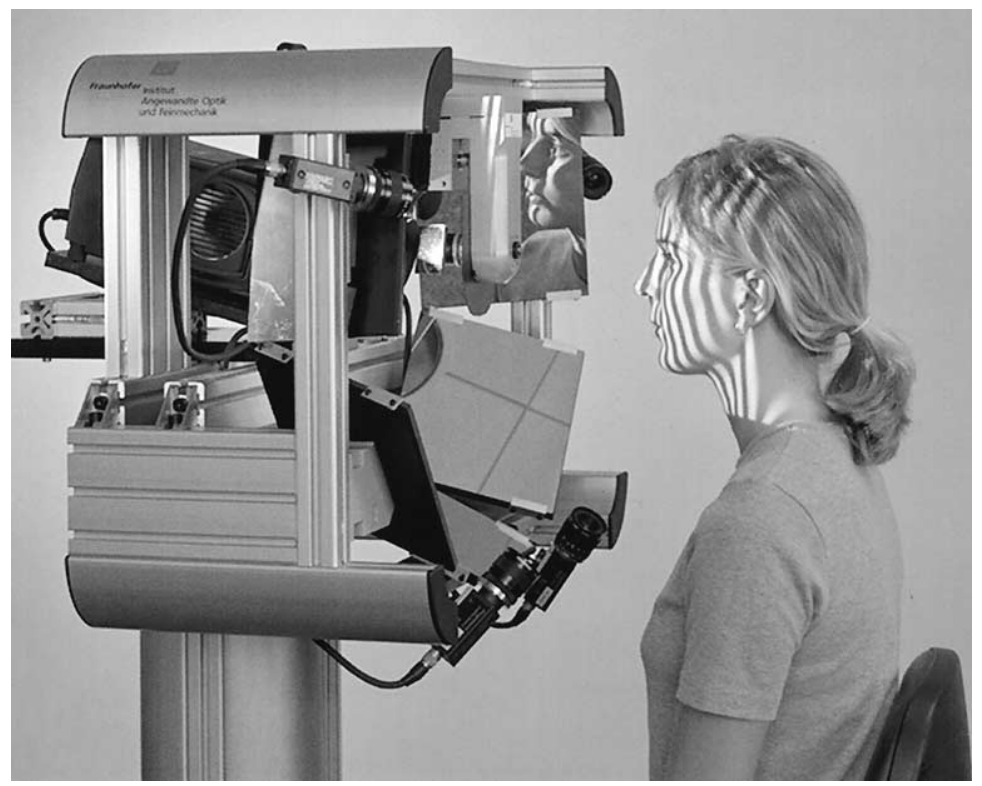

Fig. 2. Measurement instrumentation and light projected on subject's face.

the cameras as well as 3 of the projection directions are directed from below to measure the chin. Using this technique, a general view of the body part is obtained automatically without any additional software manipulations, such as picture matching. The duration time of recording up to the $3-\mathrm{D}$ point cloud is approximately 20 seconds. The measuring accuracy is purported by the manufacturer to be less than $100 \mu \mathrm{m}$. Thus, points with a distance of $100 \mu \mathrm{m}$ and greater can be recorded sepa- rately. With this technology, the patient's physical and psychological stress may be reduced. This article describes a technique for the optical modeling of an ocular prosthesis.

\section{TECHNIQUE}

The arrangement of the measuring point is demonstrated in the sketch in Figure 1. Listed below is the 


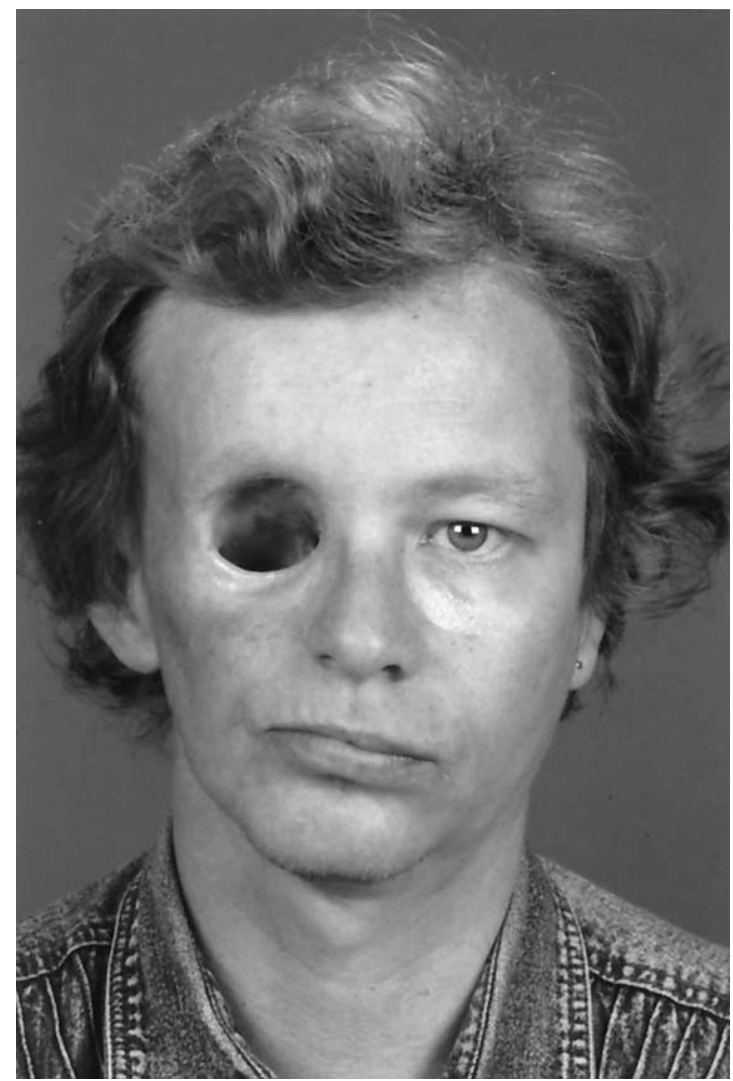

Fig. 3. Patient with orbital defect.

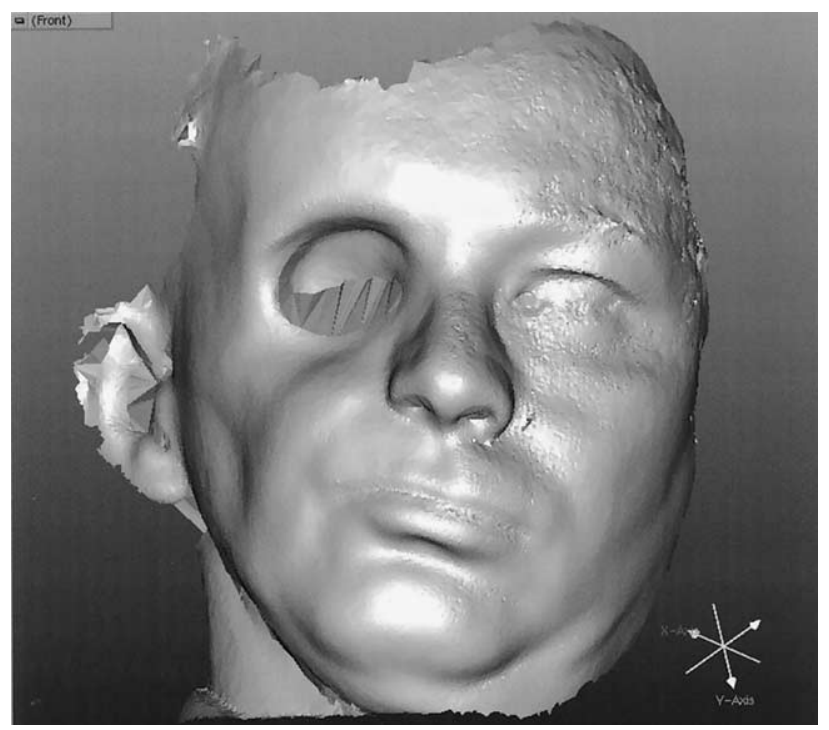

Fig. 4. CAD-model based on digitized data of patient from Figure 3 .

order for the optical molding and use of data for the fabrication of an orbital prosthesis:

l. Inform the patient about the measuring procedure.

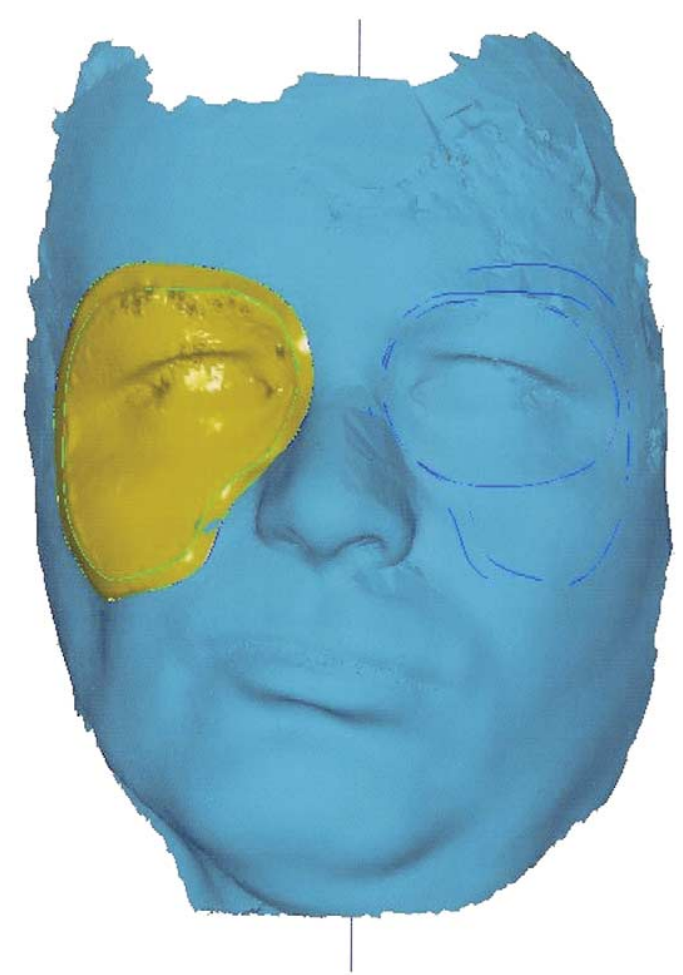

Fig. 5. CAD-model of patient's face (cyan) together with CAD-model (yellow) of prosthesis pattern.

2. Initialize and calibrate the measuring system ("kolibri-mobile"; IVB, Jena, Germany) according to 2 bowls of known diameter and distance according to the manufacturer's recommendation.

3. Position the patient and stabilize the relevant body part.

4. Adjust the camera position and shutter to the patient's area of interest (face).

5. Expose the body part to structured light and optically record the body part (Fig. 2).

6. Transfer and save the data into the computer (A 2000 D; Ingenieurbüro Redlich GmbH, Jena, Germany) as an *.arg-file. Change these data in ASCII format on the computer (spline surface as IGES format). Process the data with software (SURFACER, version 10.5, alphacam; GmbH, Schorndorf, Germany).

7. Generate a CAD model (Figs. 3, 4, and 5).

8. Transfer the CAD model into a physical model by means of a rapid prototyping procedure ("thermojet-model") (Fig. 6). Develop the model on a 3-D model printer ("ThermoJet"; 3D Systems, Darmstadt, Germany). Control the fabrication of the model using software (3D ThermoJet Client Manager, version $1.0 ; 3 \mathrm{D}$-Systems). Use the thermopolymer (ThermoJet $88 ; 3 \mathrm{D}$ Systems) to create the prosthesis pattern. 


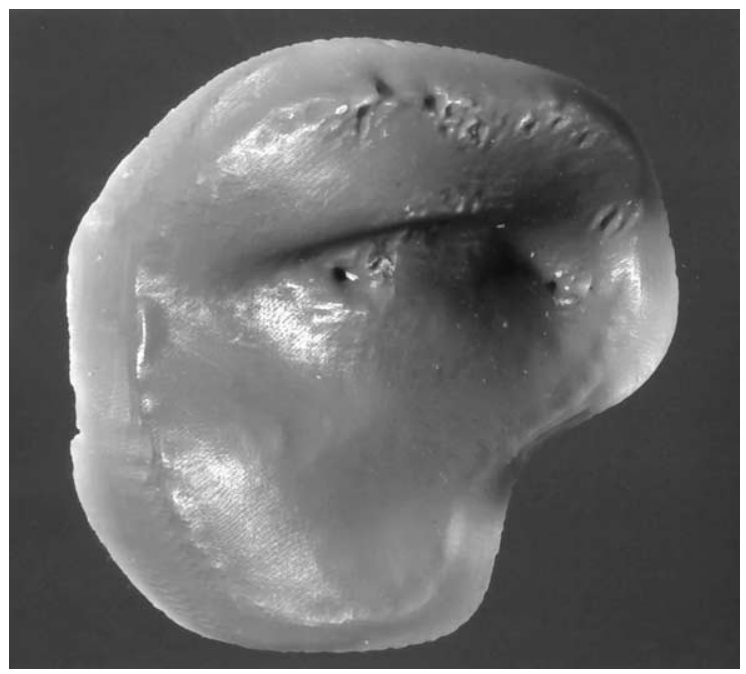

Fig. 6. Physical model of prosthesis pattern from rapid prototyping process.

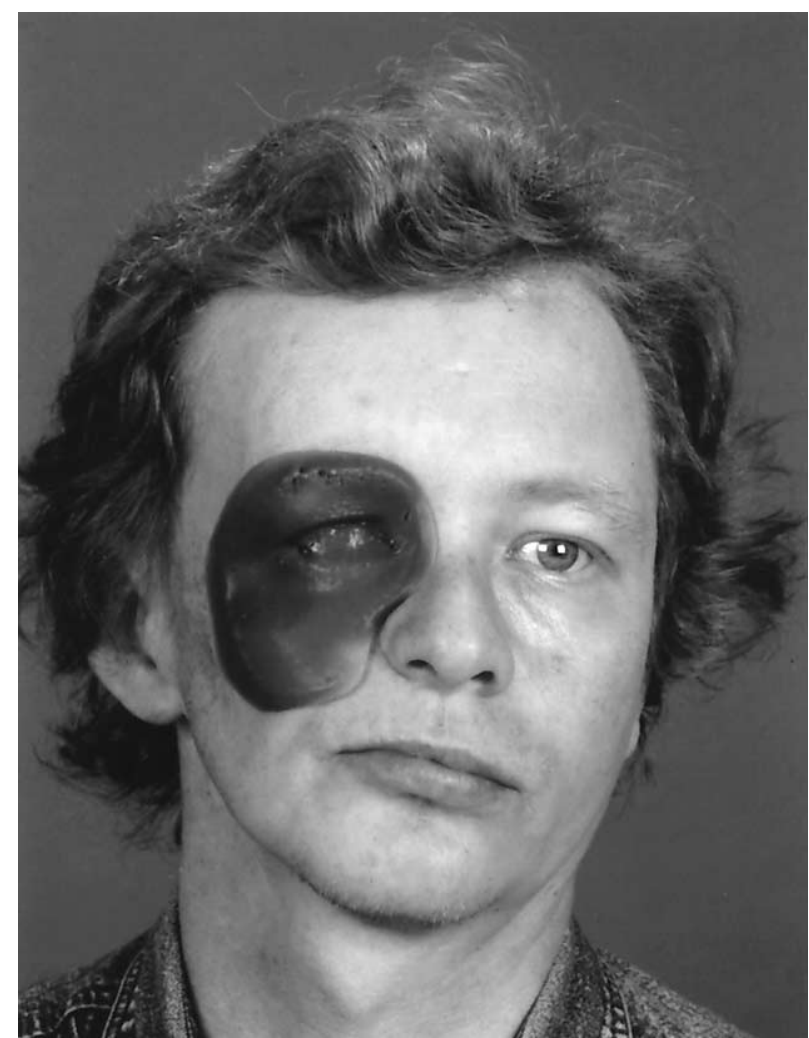

Fig. 7. Patient with prosthesis pattern without corrections.

9. Place the thermojet model on the patient to allow for modification and correction (Fig. 7). Evaluate the contours and fit of the marginal areas of the maxillofacial prosthesis and the overall design. Make corrections by reducing the thermopolymer with burs, scis-

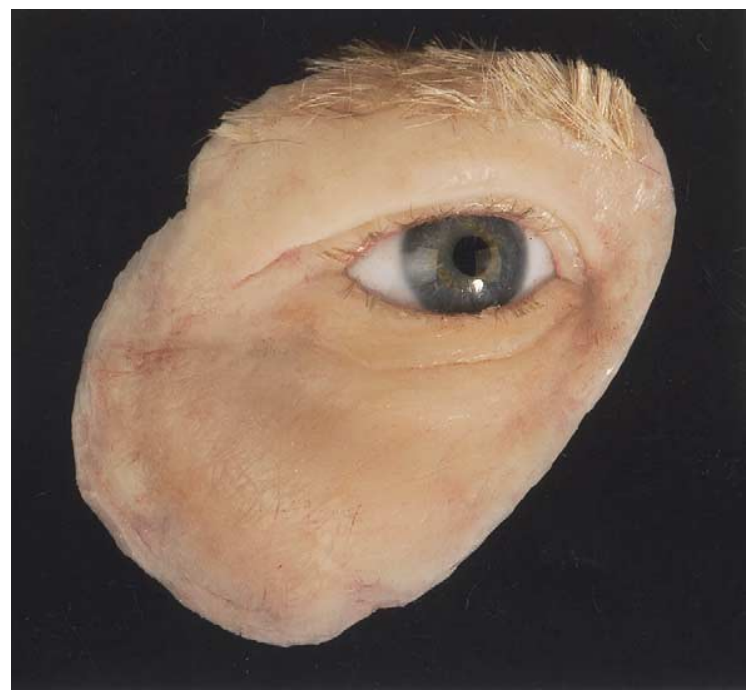

Fig. 8. Definitive prosthesis.

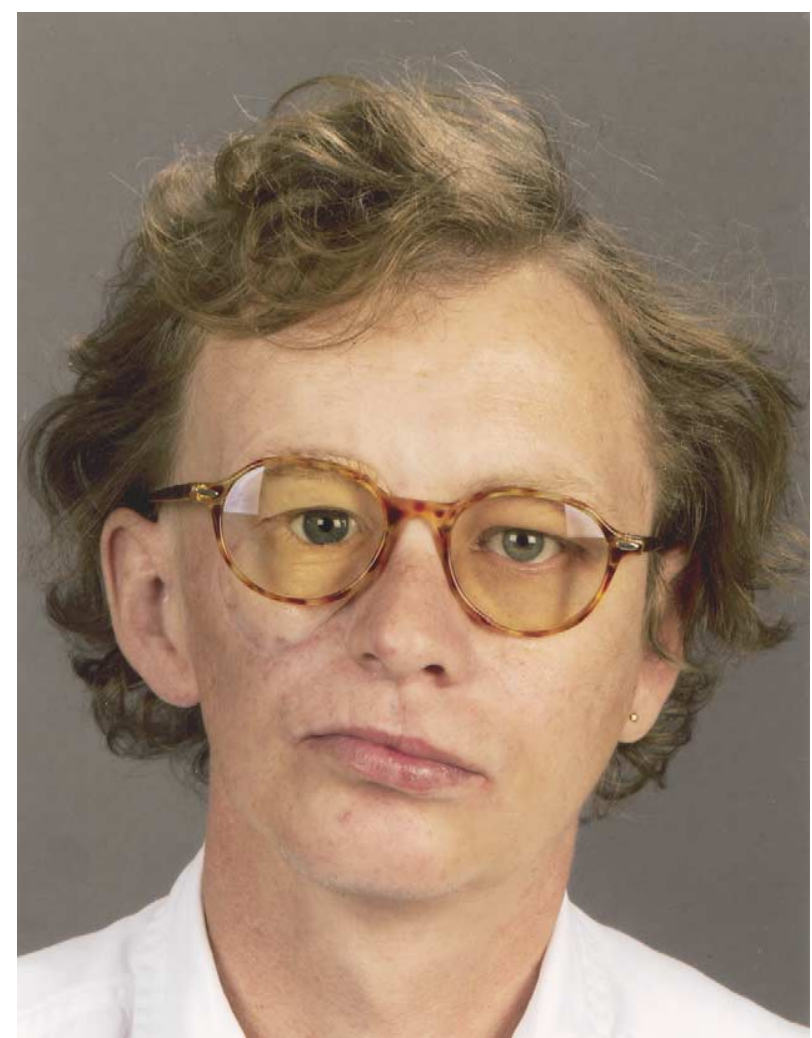

Fig. 9. Definitive prosthesis on patient. Glasses worn by patient are for vision correction and not attached to prosthesis.

sors, and a hot knife or wax additions directly to the surface or margins of the thermopolymer. Invite the patient to express his or her opinion of the prosthesis.

10. Transfer the thermojet-model to a material for the definitive orbital prosthesis. The prosthesis is made 
using the prosthetic material of choice by the anaplastologist or dental technician, whose artistic competence may influence the result (Figs. 8 and 9).

\section{DISCUSSION}

Conventional impression materials have been used for decades in dentistry and maxillofacial prosthetics. The form of optical modeling described in this article uses "normal" light and does not expose the patient to radiation as does a CT or MRI.

The representation of the digital data is based on the following principles. For paired areas (such as an orbital defect, as illustrated), the reflection of the data from the healthy side is used. Subsequently, the difference in the data between the healthy and the diseased side is determined. This is the data record used to derive a physical pattern of the replacement body part. For paired areas that cannot be recorded using only one optical modeling, the first step requires several individual recordings. The data are then matched, for example, in a situation following resection of an ear.

Unpaired facial parts, such as a total rhinectomy, pose a particular challenge. In this situation, digitized data from test subjects or the patient's own representations (pictures) from the period before the resection must be included in the process. This type of optical database is also used for communication with the patient before the maxillofacial prosthesis is made. Prior to this technique, only plaster model banks, samples of defects, and prostheses for other patients existed as aids to patient communication.

The process described can be used to manufacture maxillofacial prostheses, extraoral radiation devices, individual respiratory masks, and facial protection devices for athletes.

\section{SUMMARY}

This article describes the use of structured light to produce a digital impression of the face or other body parts. This procedure may avoid the stress experienced by patients when conventional modeling methods are used or exposure to radiation when using a CT or MRI. After processing the digital data of the optical modeling, the definitive prosthesis is produced based on this data.

\section{REFERENCES}

1. Öwall B, Käyser AF, Carlsson GE. Prosthodontics. Principles and management strategies. London: Mosby-Wolfe; 1996. p. 201-21.

2. Mathews MF, Smith RM, Sutton AJ, Hudson R. The ocular impression: a review of the literature and presentation of an alternate technique. J Prosthodont 2000;9:210-6.

3. Idris B, Houston F, Claffey. Comparison of the dimensional accuracy of one- and two-step techniques with the use of putty/wash addition silicone impression materials. J Prosthet Dent 1995;74:535-41.

4. Thomas KF. Impression and facial materials. London: Quintessence; 1994, p. 39-53.

5. Swift EJ Jr. Elastomeric impression materials. lowa Dent J 1988;74:39-40.

6. Rose LA. Automatic mixing machine. J Clin Orthod 1982;16:104-5.

7. Association Council on Dental Materials, Instruments and Equipment. Vinyl polysiloxane impression materials: a status report. J Am Dent Assoc 1990;120:595-6, 598, 600.

8. Habakuk SW, Potter-Ratzlaff E. Impressions for facial prostheses. In: McKinstry RE, editor. Fundamentals of facial prosthetics. Arlington: ABI Professional Publication; 1995. p. 31-45.

9. Penkner K, Santler G, Mayer W, Pierer G, Lorenzoni M. Fabricating auricular prostheses using three-dimensional soft tissue models. J Prosthet Dent 1999;82:482-4.

10. Lambrecht JT. 3D modeling technology in oral and maxillofacial surgery. Chicago-Berlin: Quintessence Pub; 1995, p. 25-44.

11. Arnett GW, Jelic JS, Kim J, Cummings DR, Beress A, Worley CM Jr, et al. Soft tissue cephalometric analysis: diagnosis and treatment planning of dentofacial deformity. Am J Orthod Dentofacial Orthop 1999;116:239.

12. Persson $M$, Andersson $M$, Bergman B. The accuracy of a high-precision digitizer for CAD/CAM of crowns. J Prosthet Dent 1995;74:223-9.

13. Willer J, Rossbach A, Weber HP. Computer-assisted milling of dental restorations using a new CAD/CAM data acquisition system. J Prosthet Dent 1998;80:346-53.

14. Luthardt RG, Sandkuhl O, Herold V, Walter MH. Accuracy of mechanical digitizing with CAD/DAM system for fixed restorations. Int J Prosthodont 2001; $14: 146-51$.

15. Wu M, Tinschert J, Augthun M, Wagner I, Schadlich-Stubenrauch J, Sahm PR, et al. Application of laser measuring, numerical simulation and rapid prototyping to titanium dental castings. Dent Mater 2001;17:102-8.

16. Asundi AK, Wensen Z. Mapping algorithma for 360-deg. profilometry with time delayed integration imaging. Opt Eng 1999;38:339-44.

17. Schreiber W, Notni G. Theory and arrangements of self-calibrating wholebody three-dimensional measurement systems using fringe projection technique. Opt Eng 2000;39:159-69.

Reprint requests to:

Dr Bernd Reitemeier

Department of Prosthetic Dentistry

Medical Faculty Carl Gustav Carus

TeChNical University of Dresden

FETSCHERSTR 74

01307 DRESDEN, GERMANY

FAX: 49-351-458-4368

E-MAIL: reitemei@rcs.urz.tu-dresden.de

0022-3913/\$30.00

Copyright (C) 2004 by The Editorial Council of The Journal of Prosthetic Dentistry.

doi:10.1016/j.prosdent.2003.10.010 